15 Dubos R, Savage D, Schaedler R. Biological Freudianism: lasting effects of early environmental influences. Pediatrics 1966;38:789-800.

16 Winick $M, N o b l e A$. Cellular response in rats during malnution at vaious ages. I Nutr 1966;89:300-6.

17 Swenne I, Crace CJ, Milner RDG. Persistent impairment of insulin secretory response to glucose in adult rats after limited period of protein-calori malnurition early in life. Diabetes 1987:36:454-8.

18 Andrew $M$, Paes B, Johnston $M$. Development of the hemostatic system in the neonate and young infant. Am $\mathcal{F}$ Pediatr Hematol Oncol 1990;12:95-104.

9 Barker DJP, Godfrey KM, Osmond C, Bull A. The relation of fetal length, ponderal index and head circumference to blood pressure and the risk of hypertension in adult life. Paediatr Pernat Eprdemiol (in press).

20 Gruenwald P. Chronic fetal distress and placental insufficiency. Biol Neona $1963 ; 5: 215-65$

21 Holmes GE, Miller HC, Hassanein K, Lansky SB, Goggin JE. Postnatal somatic growth in infants with atypical fetal growth patterns. Am $\mathcal{f}$ Dis Child 1977; 131:1078-83.

22 Villar J, Smeriglio V, Martorell $\mathrm{R}$, Brown $\mathrm{CH}$, Klein RE. Heterogeneous growth and mental development of intrauterine growth retarded infants during ane firs 3 yen of life. Pediat 1984;74:783-91.

23 Kannel WB, Philip AW, Castelli WP, D'Agostino RB. Fibrinogen and risk of cardiovascular disease. The Framlingham study. fAMA 1987;258:1183-6 24 Wilhelmsen L, Svardsudd K, Korsan-Bengtsen K, Larsson B, Welin L, Tibblin G. Fibrinogen as a risk factor for stroke and myocardial infarction. New Engl F Med 1984;311:501-5.

25 Hales CN, Barker DJP, Clark PMS, Cox LJ, FAll C, Osmond C, et al. Fetal and infant growth and impaired glucose tolerance at age 64 years. $B M \gamma$ 1991;303:1019-22.

(Accepted 17 October 1991)
Walton Hospital, Liverpool

IA MacFarlane, $M D$

consultant physician

G V Gill, MD, consultant

physician

E Masson, MD, senior registrar

in medicine

H M Prison, Liverpool

N H Tucker, MB, head of medical services

Correspondence to:

Dr I A MacFarlane,

The Diabetes Centre,

Walton Hospital, Liverpool

L91 AE.

BMF 1992;304:152-5 ideal diabetic care by medical personnel trained in diabetes during long prison sentences.

In 1989 one of us (IAM), a consultant physician and diabetologist in Liverpool, became the visiting physician to HM Prison, Walton, Liverpool. This entails holding an afternoon medical clinic about every two weeks, when any medical problems noted by the prison medical staff are referred for a further opinion. Common conditions include ischaemic heart disease, hypertension, and diabetes. There has been no previous prospective study of the management of diabetes in British prisons. This paper therefore examines in detail all prisoners with diabetes seen in the clinic over 22 months and reports their metabolic control. We also discuss methods of achieving optimal diabetic care in a prison environment. Between the initial assessment by the visiting consultant diabetologist and a second assessment 10 weeks later glycated haemoglobin concentrations had fallen from 10.8 (SD 2.9 ) $\%$ to $9.8(2.4) \%$ $(\mathbf{p}<0.05)$ in prisoners with insulin dependent diabetes and from $8.7(1.9) \%$ to $7.6(1.2) \%(p<0.05)$ in those with non-insulin dependent diabetes. Good glycaemic control continued, a mean glycated haemoglobin concentration of $7.6(1.5) \%$ being recorded in seven men remaining in prison for six to 18 months. Mean body mass index (weight (kg)/ (height $(\mathbf{m}))^{2}$ ) did not change during the study (insulin dependent prisoners 23.3 (SD 2.1), non-insulin dependent prisoners $27 \cdot 9(3 \cdot 8)$ ).

Conclusions-Good diabetic metabolic control is usual in prison, probably due to the rigid dietary regimen, no alcohol, and compliance with treatment. Many younger men had defaulted from their home diabetic clinics, and imprisonment allowed screening for diabetic complications and reassessment of treatment. Structured diabetic care should be offered in all prisons.

\section{Introduction}

The conditions experienced by people in custody in the United Kingdom have received considerable attention recently, particularly after the serious disturbances in prisons in Manchester and elsewhere during 1990. Also there has been much debate concerning the standards of health care in British prisons. ${ }^{1-5} \mathrm{~A}$ major problem is the paucity of data on specific medical conditions, although suicide, drug abuse, and HIV infection have received particular attention ${ }^{6-8}$ In a previous report we highlighted difficulties in delivering diabetic care in prisons. ${ }^{9}$ These included self induced diabetic ketoacidosis by prisoners refusing insulin in order to be transferred to the local hospital; prison staff misinterpreting poorly controlled diabetes as "acting up" by prisoners; and difficulty of delivering

\section{Patients and methods}

Walton prison has about 1500 inmates and is one of the largest prisons in Britain. During 22 months (August 1989 to May 1991) all prisoners with diabetes identified by the prison medical officers were referred to the medical clinic held in the prison hospital. For each prisoner with diabetes the following were recorded: weight and height; type, duration, metabolic control (glycated haemoglobin concentration), and treatment of the diabetes; diabetic complications present; other medical illnesses and treatments; and smoking habits. A record was kept of alterations in the medical management initiated in the clinic. The views of the prisoners on the prison diet, exercise facilities, and medical management in prison were also recorded

The prison has a mixture of remand (before conviction; roughly $20-25 \%$ ) and convicted prisoners, all male. The period of remand may vary from days to many months. Sentences also vary from a few days to life imprisonment but are usually between four and 18 months. Walton is a traditional Victorian prison and is undergoing extensive refurbishment. Many prisoners, however, continue to share cells with communal sanitation facilities. Exercise is usually limited to about an hour's walking in the yard each day. The 60 bed prison hospital is staffed by five full time medical officers and is a referral centre for major medical, surgical, and psychiatric problems occurring in smaller prisons in the north west. Many prisoners are moved sentence.

All the prisoners with diabetes are entitled to extra fruit, yoghourt, and night time digestive biscuits (to reduce the risk of nocturnal hypoglycaemia). The administration of oral hypoglycaemic drugs and insulin injections is supervised by the prison hospital officers. Prisoners are not allowed to keep tablets, to other establishments several times during their 
syringes, and needles in their possession. The nondiabetic reference range for the glycated haemoglobin assay was $4 \cdot 0-8 \cdot 0 \%$. Student's paired $t$ test was used for statistical analysis.

\section{Results}

During the 22 months 42 prisoners with diabetes were seen. In addition, one prisoner on remand claimed to have insulin dependent diabetes. He, however, had been admitted to many hospitals, claiming to have insulin dependent diabetes - and also epilepsybut, in fact, had neither condition. Twenty three of the 42 prisoners had insulin dependent diabetes and 19 non-insulin dependent diabetes. Table I gives the details of the 42 prisoners.

TABLE I-Details of 42 diabetic prisoners assessed

\begin{tabular}{|c|c|c|}
\hline & $\begin{array}{c}\text { Prisoners with } \\
\text { insulin dependent } \\
\text { diabetes } \\
(\mathbf{n}=23)\end{array}$ & $\begin{array}{c}\text { Prisoners with } \\
\text { non-insulin } \\
\text { dependent diabetes } \\
(n=19)\end{array}$ \\
\hline Treatment & Insulin & $\begin{array}{l}\text { Diet (7), } \\
\text { glibenclamide (11), } \\
\text { metformin (1) }\end{array}$ \\
\hline $\begin{array}{l}\text { Median age (range) (years) } \\
\text { Median duration of diabetes } \\
\text { (range) (years) }\end{array}$ & $\begin{array}{l}26(21-62) \\
7 \cdot 0(0 \cdot 1-25 \cdot 0)\end{array}$ & $\begin{array}{l}55(35-72) \\
3 \cdot 0(0 \cdot 1-25 \cdot 0)\end{array}$ \\
\hline
\end{tabular}

Three prisoners had recently developed insulin dependent diabetes in other prisons. They had been established on insulin injections in a local hospital and then been transferred to Walton prison. Non-insulin dependent diabetes had recently been diagnosed in three prisoners with coexisting cardiovascular disease, and a raised blood glucose concentration had been discovered during routine biochemical testing. The time spent in prison by both groups of prisoners before assessment in the medical clinic was similar (median 12 weeks by prisoners with insulin dependent diabetes, 14 weeks by those with non-insulin dependent diabetes).

Treatment of diabetes-Twenty one prisoners with insulin dependent diabetes were taking twice daily insulin injections (soluble and intermediate insulin, mostly of the premixed variety), and one was taking three injections daily. One prisoner took only one injection of premixed insulin in the morning and refused to have two injections. Seven of the non-insulin dependent group were treated with diet alone, 11 were taking glibenclamide, and one was taking metformin.

Diabetic complications-Six prisoners with insulin dependent diabetes and three with non-insulin dependent diabetes had evidence of background diabetic retinopathy (scattered microaneurysms). One noninsulin dependent prisoner was registered blind and had received extensive laser treatment because of severe retinopathy. Three insulin dependent prisoners and one non-insulin dependent prisoner had symptoms of peripheral neuropathy affecting the feet. None had proteinuria (Albustix) and all had normal serum creatinine concentrations.

Intervention by clinic physician - Eight prisoners with insulin dependent diabetes had major changes made to their insulin regimens by the clinic physician (increase in dose of insulin in six cases, reduction in dose in two (because of mild hypoglycaemia)). Two insulin dependent prisoners with troublesome neuropathic symptoms began oral imipramine. Insulin injections were stopped in one non-insulin dependent prisoner and dietary treatment substituted. One non-insulin dependent prisoner had the dose of glibenclamide increased, and in another the dose was reduced because of mild hypoglycaemic symptoms. Much simple dietary advice was given to both insulin dependent and non-insulin dependent prisoners. Several alterations in the drug treatment of coincidental medical conditions (angina and hypertension) were made in five of the noninsulin dependent prisoners, and one was referred for coronary angiography.

Diabetic metabolic control was assessed by glycated haemoglobin measurements. In the 36 men with established diabetes (that is, diagnosed before imprisonment) the mean glycated haemoglobin concentration was $9 \cdot 9$ (SD 2.7)\% at the initial assessment. The insulin dependent prisoners had higher glycated haemoglobin concentrations than prisoners with noninsulin dependent diabetes $(\mathrm{p}<0.02)$ (table II). Repeat measurements of glycated haemoglobin concentrations were made in 12 insulin dependent prisoners and 11 non-insulin dependent prisoners after 10 weeks. In both groups concentrations fell significantly $(p<0.05)$ Seven men (six with non-insulin dependent diabetes) remained in Walton prison for six to 18 months (median 14 months) during the study and good glycaemic control continued (mean glycated haemoglobin concentration 7.6 (SD 1.5$) \%$ at the end of the study). Mild symptomatic hypoglycaemia was reported by only a few prisoners and none required intravenous glucose.

TABLE II -Diabetic control (glycated haemoglobin concentrations) in 36 prisoners with established diabetes (diabetes diagnosed and treated before imprisonment)

\begin{tabular}{lcc}
\hline & \multicolumn{2}{c}{ Mean (SD) glycated haemoglobin (\%) } \\
\cline { 2 - 3 } & $\begin{array}{c}\text { Prisoners with } \\
\text { insulin dependent } \\
\text { diabetes }\end{array}$ & $\begin{array}{c}\text { Prisoners with } \\
\text { non-insulin } \\
\text { dependent diabetes }\end{array}$ \\
\hline First assessment $\dagger$ & $10 \cdot 8(2 \cdot 9)[n=20]$ & $8 \cdot 7(1 \cdot 9)[n=16]$ \\
Second assessmentł & $9 \cdot 8(2 \cdot 4)[n=12]$ & $7 \cdot 6(1 \cdot 2)[n=11]$
\end{tabular}

${ }^{\star}$ Before first assessment prisoners with insulin dependent diabetes had bee in custody a median of 12 weeks (range 2-50) and those with non-insuli dependent diabetes a median of 14 weeks (range 2-52).

†Prisoners with insulin dependent diabetes $v$ prisoners with non-insulin dependent diabetes: $\mathrm{p}<0.02$.

$\ddagger$ First assessment $v$ second assessment: prisoners with insulin dependen diabetes $\mathrm{p}<0.05$; prisoners with non-insulin dependent diabetes $\mathrm{p}<0.05$ (paired $t$ test)

Body mass index was computed by dividing weight (kg) by the square of the height $\left(\mathrm{m}^{2}\right) \cdot{ }^{10} \mathrm{An}$ index of 20.0-24.9 was considered acceptable, $25 \cdot 0-29 \cdot 9$ overweight, and 30.0 or over obese. The 23 prisoners with insulin dependent disease had a normal mean body mass index $(23 \cdot 3$ (SD 2.1)) and the 19 with non-insulin dependent disease a mean index in the overweight range $(27.9(3.8))$. Body mass index did not change significantly in the prisoners reviewed after 10 weeks.

Other medical illnesses-Four prisoners with insulin dependent diabetes admitted to intravenous drug abuse and many to excessive alcohol consumption before imprisonment. One other insulin dependent prisoner had severe chronic pancreatitis secondary to alcoholsm. In the non-insulin dependent group there was a considerable amount of other medical disease. This included hypertension (six cases), angina (seven), previous myocardial infarction (five), treated heart failure (two), previous cerebrovascular accident (two), and various other problems, including obstructive airways disease, severe obesity, gout, recurrent depression, peptic ulceration, peripheral vascular disease and hyperlipidaemia. Overall, nine prisoners in the non-insulin dependent group had symptomatic macroangiopathic disease and were taking multiple drugs.

Smoking-Nineteen of the 23 insulin dependent prisoners and 11 of the 19 non-insulin dependent prisoners admitted to smoking. Many said their smoking had increased in prison, mainly owing to the boredom of being locked up for long periods. Three non-smokers complained about occupying cells with prisoners who smoked.

Prisoners' views on environment-Of particular relevance to the management of diabetes was the prison 
diet and the availability of exercise. Four of the 42 prisoners thought that prison food was "smashing and just like home"; 22 were not particularly unhappy about the food and thought there was enough and that it was of reasonable content; and 16 were unhappy about the prison diet. Three of this last group were of Asian origin, and their main complaint was that the food was nothing like what they ate at home. Three insulin dependent prisoners thought that there was not enough food and were worried about hypoglycaemia occurring during the night. The other prisoners thought that the prison diet did not include enough variety - for example, fresh fruit and vegetables - and that there was too much fat (too "stodgy"). Several wished to see a qualified dietitian for advice on a healthy diet (particularly those with coincidental cardiovascular disease) and how to avoid hypoglycaemia. Asked about exercise, 34 of the 42 prisoners were happy with the amount of exercise they were able to take each day, and several did a regular exercise programme in their cells. The other eight prisoners thought they did not get enough exercise, and several would have liked more exercise in order to lose weight.

Diabetic care before imprisonment-The 36 men with established diabetes before imprisonment came from all over England (mainly the north west), and one lived in Denmark. Eleven of the 20 with established insulin dependent disease admitted to being chronic poor attenders at their home diabetic clinic and had not received any form of diabetic care for years. Most of the non-insulin dependent prisoners claimed to attend their home diabetic clinics regularly. However, they were probably attending hospital clinics for management of other medical problems in addition to diabetes.

\section{Discussion}

In 1991 there were some 47000 prisoners in the United Kingdom, of whom $95 \%$ were male and aged $15-55 .^{1}$ This study, carried out in one prison over 22 months, assessed 42 prisoners with diabetes. Six were diagnosed in prison and most of the others were seen within two to three months of reception into the prison system. As expected, over half of the prisoners with diabetes $(n=23)$ were young men with insulin dependent disease. Most of these young men faced prison sentences of less than two years, which are often reduced by one third or more because of remission or parole. Many of the insulin dependent prisoners had been poor attenders at their home diabetic clinic, and in some cases their assessment in the prison medical clinic was the first for several years. Comparatively few had diabetic complications, and severe hypoglycaemia was not reported.

In contrast, the non-insulin dependent prisoners were a very unhealthy group of middle aged men. Many had severe problems with macrovascular disease and took multiple drugs, often for hypertension and angina. These older prisoners claimed that their compliance with treatment and attendance at outside clinics before imprisonment had been reasonable.

Diabetic metabolic control (judged by glycated haemoglobin concentration) was good overall for the men whose diabetes had been diagnosed before imprisonment. Most of the prisoners had glycated haemoglobin concentrations of less than $10.0 \%$, which compares favourably with findings in hospital diabetic clinics. A recent survey, using the same assay method and laboratory, found the mean glycated haemoglobin concentration in young diabetic adults to be $10.5 \%$. $^{11}$ This reasonable diabetic control was present before assessment and alteration of treatment in the prison medical clinic.
Repeat measurements of glycated haemoglobin concentration were not possible in all prisoners because of either release from prison or a move to another prison. However, further measurements in 23 of the men with pre-existing diabetes showed a significant fall, both in prisoners with insulin dependent diabetes and in those with non-insulin dependent diabetes, indicating an improvement in diabetic metabolic control (table II). Possibly the reasonable diabetic control at first assessment and improvement in control over the next 10 weeks was due to the prison environment - that is, the structured daily routine and rigid diet. In some cases, however, the intervention of the clinic physician may have contributed.

Why should the prison environment be compatible with good diabetic control? Meals are provided regularly by mass catering and tend to be fatty and repetitive. Prisoners have limited but regular periods of exercise. The administration of oral hypoglycaemic agents and insulin injections is supervised. Probably many of these diabetic subjects had led chaotic lifestyles before imprisonment, with irregular meals, excessive alcohol, little exercise, and poor compliance with treatment regimens. There is no access to alcohol in prison, and no readily available "junk food." Diabetic prisoners are, however, entitled to extra fruit, yoghourt, and night time biscuits.

\section{NEED FOR GUIDELINES}

Caution must be exercised in extrapolating these findings to the prison population as a whole. Walton prison is a referral centre for prisoners with medical problems and probably houses a larger population of diabetic prisoners than other establishments. Also, in many prisons the visiting physician (if there is one) is not a specialist diabetologist.

This study has shown that the prison environment can be compatible with good diabetic metabolic control, and there were no serious episodes of hypoglycaemia. There were no instances of manipulation of the diabetes by prisoners during the study, which may have been due to their respecting the particular attention paid to them. Clearly the medical clinic at Walton prison cannot be implemented in all prison establishments throughout the United Kingdom, and there is an urgent need for guidelines for diabetic care for all prisoners. This is being examined by a working party of the British Diabetic Association. All prisoners with diabetes need access to experienced doctors in diabetic care who can monitor diabetic control, prescribe diabetic treatment regimens, and screen for complications. ${ }^{12}$ There is an obvious need for specialist nurses to educate both prisoners with diabetes and prison staff in diabetic care. A visiting dietitian should advise on dietary requirements. In addition, chiropodists, opticians, and ophthalmic surgeons should be readily available.

A possible development which may be a solution in those prisons that do not have access to a visiting consultant diabetologist is for one of the prison medical officers to run a diabetic "mini-clinic."13 This would be similar to diabetic mini-clinics which are operating successfully in general practice. Close links would clearly be required with the diabetic service at the local hospital.

In conclusion, good diabetic care can be achieved in the prison environment. Many young diabetic prisoners have defaulted from diabetic follow up at their home diabetic clinic, and prison is an opportunity to screen for diabetic complications and reassess their diabetic treatment regimens.

1 Smith R. Prison health care. London: British Medical Journal, 1984.

2 Prison Reform Trust. Prison medicine. London: Prison Reform Trust, 1985.

3 The future of the prison medical service. Lancet 1985;ii:755-6.

4 Shackled, shameful and shoddy. Lancet 1988; i: 1402-4. 
5 Bluglass R. Recruitment and training of prison doctors. BMF 1990;301: $249-50$.

6 Smith R. Failure of suicide prevention measures at Risley. BMF 1988;297:89.

7 Smith R. Taken from this place and hanged by the neck. $B M \mathcal{F}$ 1991;302:64-5.

8 Smith R. Root and branch reform of prisons. BMf 1991;302:550-1.

9 Gill GV, MacFarlane IA. Problems of diabetes in prison. BMf 1989;298: 221-3.

10 Garrow JS. Weight penalties. BMf 1979;ii:1171-2.

11 Fisken RA, Chan AW, Hanlon A, MacFarlane IA. Changes in fructosamine do not parallel changes in glycated haemoglobin in young adults with type diabetes. Clin Chim Acta 1990;191:79-86.

12 British Diabetic Association. What professional supervision adults with diabetes should expect. Balance 1988; No 105:5.

13 Home P, Walford S. Diabetes care: whose responsibility? BMF 1984;289:

\title{
Diurnal variation in incidence of stroke: Oxfordshire community stroke project
}

\author{
Stephen J Wroe, Peter Sandercock, John Bamford, Martin Dennis, Jim Slattery, Charles Warlow
}

Abstract

Objective-To determine whether diurnal variation occurs in the onset of stroke.

Design-Community based study over four years. Setting-Oxfordshire, United Kingdom.

Subjects -105000 people, of whom 675 had a first ever stroke. 545 had a cerebral infarction, 66 had primary intracerebral haemorrhage, 33 had subarachnoid haemorrhage, and in 31 the type of stroke was not known.

Main outcome measures-Time of stroke and degree of activity at onset.

Results-In the 578 patients for whom it was known whether onset occurred while asleep or awake, the proportion with onset during sleep was $25 \%(135 / 545)$ for cerebral infarction, $17 \%(11 / 66)$ for primary intracerebral haemorrhage, and $0 \%(0 / 33)$ for subarachnoid haemorrhage. This difference persisted if patients in whom it was not known whether they were asleep or awake at onset were classed as asleep. For all stroke types together there was a significant $\left(\chi^{2}=218.7, p<0.001\right)$ diurnal variation with a morning peak between 0800 and 1000 , which persisted even after allowing for strokes first noted on waking by redistributing the hour of onset through the preceding eight hours $\left(\chi^{2}=47, p<0.001\right)$. A significant diurnal variation was also found in the onset of cerebral infarction (peak 0800-1000, $\left.\chi^{2}=208.4, p<0.001\right)$. Fewer patients had other forms of stroke and the diurnal variations for primary intracerebral haemorrhage (peak 1000-1200) and subarachnoid haemorrhage (peaks 0800-1000 and 1800-2000) were not significant. There seemed to be a second smaller peak for all types of stroke.

Conclusions - All types of stroke are most likely to occur after waking in the morning. The cause of the circadian variation requires further study.

\section{Introduction}

Proof of a circadian rhythm in the occurrence of cerebral infarction and other types of stroke might provide clues to factors which immediately precipitate these events, which in turn might lead to more rational treatments. Several studies have addressed this issue but have produced rather conflicting results, some suggesting that strokes occur most often during the night $^{12}$ and others a morning peak. ${ }^{3-7}$ These studies included hospital based series, in which there is inevitably selection of cases, ${ }^{3-6}$ and other studies did not differentiate between types of stroke, which may have different circadian rhythms. Some studies fail to distinguish between strokes occurring while awake or sleeping ${ }^{18}$ and the time of onset of stroke may not be recorded accurately in retrospective studies. ${ }^{1}$

To investigate the possibility that strokes occur more often at certain times of the day and that different types of stroke have different circadian variation we examined data from a community based stroke register in which the type of stroke was determined in $90 \%$ of cases.

\section{Patients and methods}

The Oxfordshire community stroke project is a prospective, community based study of first ever stroke in a defined population of about 105000 people in Oxfordshire. Definitions of type of stroke and details of the methods used in the project are given elsewhere. ${ }^{910}$ Six hundred and seventy five cases of clinically definite first ever stroke were registered over four years. Complete case ascertainment was obtained through the collaboration of general practitioners and examination of hospital admission registers, the Oxford record linkage system, and death certificates. Most patients (614): were seen by a neurologist in the study at a median time of four days after the onset of symptoms, and a witness was interviewed when no history was available from the patient.

In all, 574 had computed tomography or a postmortem examination. In the remaining patients the type of stroke was determined with the Guy's Hospital diagnostic score. ${ }^{.1}$ Stroke type was classified as cerebral infarction, primary intracerebral haemorrahge, or subarachnoid haemorrahge (all cases of subarachnoid haemorrhage were included in the study). ${ }^{10}$ Cerebral infarction was further classified on the basis of clinical features as middle cerebral artery territory (total anterior circulation infarct), cortical (partial anterior circulation infarct), lacunar, or posterior circulation infarction. ${ }^{12}$

The time of onset of stroke was recorded by the neurologist at the time of assessment. In patients who first noticed their stroke symptoms on waking it was presumed that the stroke had occurred during sleep. Some patients were able to state that onset was first noted on waking but could not recall the exact time of waking. Times of onset of stroke or waking with stroke were grouped into two hourly intervals for analysis. For patients who first noted symptoms on waking from sleep the time of waking was initially used as the time of onset.

A second analysis was done in which strokes with onset during sleep were assumed to have occurred at some time during the preceding eight hours and the distribution was adjusted in such a way as to minimise the $\chi^{2}$ test statistic in an analysis for non-uniform distribution of incidence. The value of $\chi^{2}$ was minimised over the set of all distributions of onset times consistent with the recorded data. This provided a conservative test of non-heterogeneity. A more sensitive Kolmogorov-Smirnov type statistic ${ }^{13}$ was also used to examine data for subarachnoid haemorrhage and primary intracerebral haemorrhage. Details of whether the patient was at rest or active when the stroke occurred were also recorded, as was a history of

Professor Warlow. 